\title{
PELAS MÃOS E PELAS MÃES: RELATO DE EXPERIÊNCIA
}

\author{
Mirele Carolina Werneque Jacomel ${ }^{1}$ \\ https://orcid.org/0000-0001-5633-8447
}

\begin{abstract}
Resumo: O presente texto consiste no relato de experiência do projeto de extensão Mulher e Mundo do Trabalho, desenvolvido no Instituto Federal do Paraná - Campus Colombo. Em parceria com o Provopar/Secretaria de Ação Social do mesmo município, a proposta oferece ações formativas a mulheres de famílias atendidas pela Secretaria supracitada, dando-lhes voz e reconhecendo os saberes que já possuem. Trata-se de uma proposta de inclusão social e de multiplicação do conhecimento, pois cada mulher compartilha tudo o que aprende no projeto e, assim, cria uma rede de proteção e de transmissão de saberes.
\end{abstract}

Palavras-chave: Trabalho. Mulher. Igualdade de gênero. Educação.

\section{BY HANDS AND BY MOTHERS: EXPERIENCE REPORT}

Abstract: This text consists of the report of experience from a extension project Women and World of Work, developed in the Instituto Federal do Paraná - Campus Colombo. In partnership with the Provopar/Social Action Secretariat of the same municipality, the proposal offers training actions to women from families assisted by the aforementioned Secretariat, giving them a voice and recognizing the knowledge they already have. It is a proposal of social inclusion and multiplication of knowledge, because each woman shares everything she learns in the project and, thus, creates a network of protection and transmission of knowledge.

Keywords: Work. Woman. Gender equality. Education.

\section{POR LAS MANOS Y LAS MADRES: RELATO DE EXPERIENCIA}

Resumen: El presente texto consiste en el relato de experiencia del proyecto de extensión Mujer y Mundo del Trabajo, desarrollado en el Instituto Federal de Paraná - Campus Colombo. En asociación con el Provopar/Secretaría de Acción Social del mismo municipio, la propuesta ofrece acciones formativas a mujeres de familias atendidas por la Secretaría arriba citada, dándoles voz y reconociendo los saberes que ya poseen. Se trata de una propuesta de inclusión social y de multiplicación del conocimiento, pues cada mujer comparte todo lo que aprende en el proyecto y así crea una red de protección y transmisión de conocimientos.

Palabras-clave: Trabajo. Mujer. Igualdad de género; Educación.

1 Doutora em Letras. Graduada em Letras e Tecnologia em Design. Professora no Instituto Federal do Paraná, Campus Colombo. E-mail: mirele.jacomel@ifpr.edu.br 
Submetido em: 02/12/2018

Aceito em: 21/12/2018.

\section{APRESENTAÇÃO E JUSTIFICATIVA}

O presente relato sintetiza parte das ações realizadas no Projeto de Extensão Mulher e Mundo do Trabalho, desenvolvido no Instituto Federal do Paraná - Campus Colombo, em parceria com o Provopar/Secretaria de Ação Social do mesmo município. O projeto tem por finalidade promover ações formativas por meio da oferta de oficinas de conhecimentos gerais, específicos e de formação empreendedora a mulheres em situação de vulnerabilidade social, assistidas pela Secretaria supracitada. A Metodologia de Avaliação e Reconhecimento de Aprendizagem Prévia (ARAP), que remete à valorização dos saberes prévios do sujeito, baliza todas as ações do projeto, buscando a sistematização do conhecimento adquirido ao longo da vida e das experiências dessas mulheres, oriundas de suas trajetórias. Nesse contexto, são realizados módulos de ensino-aprendizagem de conteúdos básicos, nos quais as participantes têm acesso a noções de comunicação, raciocínio lógico, saúde da mulher, informática básica, alimentação, educação física e mental, Arte e cotidiano, discussões sobre desigualdade de gênero e respeito à diversidade. Também são ofertadas oficinas de artesanato com tecido, conduzindo essa aprendizagem para o lado empreendedor ou mesmo para aplicação doméstica das técnicas aprendidas durante os cursos. Todas as mulheres participantes têm o compromisso de repassar algo que aprendeu nos encontros para suas filhas ou netas. Além de multiplicar o conhecimento, o objetivo é também colaborar para a emancipação humana, cultural e profissional das participantes, passando pela discussão do trabalho como princípio educativo, relacionando o debate à compreensão dos direitos da mulher, do que é empreendedorismo, economia doméstica, sustentabilidade, bem como a importância do domínio de novas tecnologias, entre outros aspectos. Com isso, observa-se que a ação de extensão contribui para o desenvolvimento pessoal e profissional, assim como tem sido impactante no desenvolvimento cultural das mulheres. Esta ação encontra-se em desenvolvimento desde outubro de 2016.

O Projeto de Extensão Mulher e Mundo do Trabalho surge sob a concepção de sociedade democrática e mais justa, que se incumbe da luta pelos direitos de 
todos. É nesse sentido que esta proposta se volta para a mulher, tendo em vista a persistente condição a que muitas mulheres ainda estão submetidas, sobretudo nas regiões mais periféricas. Basta observar nas mídias locais os inúmeros casos de opressão e diferentes tipos de violência que a mulher ainda sofre. $\mathrm{O}$ resultado dessas relações opressoras se revela no número de mulheres que não concluíram seus estudos (51\%), mães adolescentes (mais de 68 mil casos), estupros (60.018 em 2017), homicídios (4.539 em 2017), feminicídio (1.133 casos em 2017), mulheres sem emprego (48\%), agressões físicas (606 casos por dia) 2 .

O município de Colombo, localizado na região Metropolitana de Curitiba, acrescenta nas estatísticas uma diferença significativa na organização econômica e educacional e das famílias da região, pois, sua população feminina, é de $107.957^{3}$ mulheres; desse total, 68.874 são eleitoras; 103.187 residem nos perímetros urbanos; 4.770 reside na zona rural. Considerando a população feminina, apenas $36 \%$ possui trabalho formal, o que, em números reais, totaliza pouco mais de 30 mil mulheres. Esse número é $25 \%$ menor que o total de homens com trabalho formal no município de Colombo. Alguns índices podem exemplificar o cenário atual da população colombense, consultados no site do IBGE/Estatísticas de Gênero em 2017, tais como:

- Rendimento das mulheres em relação ao rendimento total da família: 37,8\%;

- Proporção de famílias em que as mulheres são responsáveis pela economia: 38,7 ;

- Razão entre o rendimento médio das mulheres em relação ao rendimento dos homens: 69,6\%;

- Mulheres sem instrução ou com Ensino Fundamental incompleto que possuem ocupação formal: $41 \%$;

- Total de mulheres com abandono escolar precoce: 4.925 ;

- Total de mulheres não alfabetizadas: 4.472 ou 5,6\% da população;

- População feminina sem instrução ou com Ensino Fundamental incompleto: $41,6 \%$;

2 Os dados foram obtidos a partir das pesquisas da Fundação Getúlio Vargas, 2017, disponível em https://portal.fgv.br/think-tank/mulheres-perdem-trabalho-apos-terem-fi lhos e Anuário Brasileiro de Segurança Pública, 2018, disponível em https://dossies.agen ciapatriciagalvao.org.br/dados-e-fontes/pesquisa/120-anuario-brasileiro-de-seguranca-publica-fbsp-2017/

Censo 2010, IBGE. 
- População feminina preta ou parda sem instrução ou Ensino Fundamental incompleto: $57 \%$;

- População feminina com Ensino Fundamental completo e Ensino Médio incompleto: $20,1 \%$;

- População feminina com Ensino Médio completo e Ensino Superior incompleto: $29,7 \%$;

- População feminina com Ensino Superior completo: 8,4\%.

Os números indicam baixos índices de formação educacional das mulheres, da mesma forma que, em termos de retribuição salarial e reconhecimento do trabalho, as mulheres ainda estão desfavorecidas. E, quando se trata das estatísticas por etnia, observa-se que a população feminina negra é mais afetada pela economia e pela exclusão. Verifica-se, nesse sentido, que a população colombense constitui um potencial campo de investigação para os Estudos de Gênero e Direitos Humanos, e para a proposição de medidas que possibilitem a mudança dos índices de desigualdade, que cooperem para a desconstrução das dicotomias de gênero e para a emancipação feminina. Dessa maneira, justifica-se esta proposição como uma ação de extensão que visa a ofertar formação educacional a mulheres em situação de vulnerabilidade social do Município de Colombo e oferecer-lhes instrumentos para qualificação profissional e para atitudes empreendedoras para transformação dessa realidade.

\section{METODOLOGIA}

A linha metodológica tem por princípio o estudo da trajetória do sujeito e dos saberes adquiridos em suas vivências. Trata-se da valorização dos conhecimentos que cada uma das mulheres traz para a convivência no projeto. Nesse processo, todos os envolvidos aprendem, professores e alunas, a partir do compartilhamento de saberes. Essa metodologia corresponde à Avaliação e Reconhecimentos de Aprendizagem Prévia (ARAP), utilizada no Programa Mulheres Mil, criado pelo Governo Federal em 2009, e que se aproxima da Pedagogia da Autonomia proposta por Paulo Freire. A inclusão torna-se objeto permanente nessa perspectiva, pois as mulheres passam a se sentir valorizadas e a pertencer a um locus de formação onde elas também protagonizam.

O trabalho, enquanto categoria de compreensão das atitudes humanas, é problematizado nesse processo como princípio educativo, por meio do qual as mulheres se percebem seres produtivos em seus tempos e espaços. Tal abordagem é 
fundamental para que elas reconheçam a necessidade de se apropriar da cultura e empoderar-se diante da estrutura social na qual estão inseridas.

A metodologia busca referência, ainda, no Sistema de Acesso, Permanência e Êxito dos Institutos Federais, instrumento facilitador no processo de implantação e implementação de políticas, projetos e ações que contemplem acolhimento, educação, qualificação e formação profissional e tecnológica, acesso ao mundo do trabalho, desenvolvimento sustentável de comunidades e inclusão de pessoas desfavorecidas. Esta concepção de acesso prioritário aos sujeitos em situação de vulnerabilidade pretende valorizar diversidades, integrando o conhecimento acadêmico ao itinerário formativo de mulheres advindas de populações não tradicionais.

As ações de aproximação consistem na interface e no diálogo com a comunidade, o que permite à instituição de ensino maior contato com a realidade das mulheres, identificando suas necessidades, desafios e sonhos, contribuindo, assim, para seu empoderamento.

É importante salientar que a parceria com a Prefeitura Municipal de Colombo garante mais qualidade ao desenvolvimento do projeto, pois os serviços sociais são garantidos para que as mulheres permaneçam nas atividades, amenizando os impedimentos que geralmente ocorrem nos casos de evasão.

\section{OBJETIVOS}

- Ofertar ações formativas a mulheres em situação de vulnerabilidade social, proporcionando sua inclusão em processos educativos formais e possibilitando o compartilhamento de experiências acumuladas em suas trajetórias;

- Promover o debate sobre gênero, direitos humanos e empoderamento da mulher, além de compreender como a práxis humana a partir das dimensões trabalho, cultura, ciência e tecnologia;

- Contribuir para a desconstrução das práticas de desigualdades de gênero e para o reconhecimento da mulher enquanto sujeito produtivo;

- Desenvolver ação de extensão de acordo com os princípios e finalidades da educação profissional e tecnológica, em articulação com o mundo do trabalho e os segmentos sociais, e com ênfase na produção, desenvolvimento e difusão de conhecimentos científicos e tecnológicos;

- Estimular uma rede de compartilhamento de saberes e proteção para as mulheres que participam do projeto; 
- Aproximar instituição de ensino e comunidade.

\section{FUNDAMENTAÇÃO TEÓRICA}

A cultura, numa acepção ampla, propicia ao indivíduo um conjunto de referências identitárias transmitidas entre as gerações. Mas a cultura também permite construir estereótipos e estabelecer conceitos que definem papéis sociais. É através da cultura que se organizam representações sociais do gênero feminino. A cultura transforma-se no cenário onde as práticas se consolidam e colaboraram para um sistema de permanência na sociedade, um processo histórico que promove hierarquias e legitima relações de poder.

O sistema sexo-gênero, termo cunhado por Maria Consuelo Campos (1992), mostra de que maneira surgem construções socioculturais nas quais são projetadas imagens do homem e da mulher. Através desse sistema é possível identificar práticas ditas masculinas e femininas que se fortalecem nas práticas e assumem lugar no inconsciente cultural dos sujeitos. São marcas de uma postura de dominação, de natureza positivista e racional, cultuando a opressão como estratégia de poder, e que foram atribuídas ao homem como traços afirmadores de seu sexo. Do mesmo modo, à mulher coube incorporar a fragilidade, a submissão e, muitas vezes, a futilidade. Dessa maneira, observa-se que as identidades de gênero delineiam-se culturalmente e, por isso, devem ser problematizadas nesse contexto.

Ainda que a problemática do sistema sexo-gênero seja objeto de muitos estudos, no campo dos Direitos Humanos a desigualdade de gênero ainda se faz presente, visto que muitas mulheres ainda são vítimas da opressão e violências tanto física quanto simbólicas. Tal cenário se vê na maneira como a mídia representa a figura feminina revestida de sedutora ou de vingativa, frágil ou fútil, quando não são portadoras de discurso androcêntrico justificado pela educação patriarcal recebida.

A estampa que a mídia oferece ao público de que a mulher vem ocupando lugares até então destinados aos homens e, por isso, garantindo sua voz na sociedade, pode, não raro, ocultar uma realidade diferente, pois, em uma análise mais pontual das profissões e dos setores nos quais as mulheres estão atuando, verifica-se que há dicotomias que ainda se reproduzem na sociedade tradicional, como é o caso dos cargos de alto escalão em grandes empresas e as profissões que ainda carregam o signo da profissão elitizada, tais como a medicina, 
direito e engenharias. As dicotomias também estão reveladas na organização de espaços e de serviços, como, por exemplo, é o caso das mulheres auxiliares de limpeza que atuam em nossas escolas, das mulheres copeiras, cargo inclusive ocupado somente por mulheres nos campi do IFPR; é também o caso da maioria das bibliotecárias, entre outros. Ainda no contexto escolar e acadêmico, essa realidade se reproduz quando se observa o número de mulheres em cursos de Licenciatura, Serviço Social, Enfermagem. Da mesma maneira, é comprovado que da população de desistentes da Educação Básica, de acordo com o IBGE, a maior parte é de mulheres. Conscientes de que as práticas culturais apregoam a ideia de que a mulher é o ser reprodutor no seio da família e que a maternidade pressupõe a estabilidade doméstica, produziu-se o discurso da necessidade da mulher organizar-se para a tripla jornada, articulando-se entre o universo público e o privado. No ano de 1986, esse debate rendeu frutos positivos com a fundação da Comissão da Questão da Mulher Trabalhadora, cuja proposta política de trabalho se fundamenta nas articulações da família, trabalho e militância sindical. Pouco tempo depois, Giulani, em 2001, enfatiza a importância da militância da mulher em movimentos sociais:

As mulheres estão conscientes de que deverão vencer dois novos desafios: no nível prático, deverão atuar nos espaços do sindicato, da empresa e da família; no nível político e cultural, deverão defender mudanças no âmbito das relações interpessoais e de gênero que são bastante diferentes nos três espaços (GIULANI, 2001, p. 654).

Três décadas depois verificam-se, hoje, dados que ainda revelam a cultura do preconceito e da violência em relação às minorias. $\mathrm{O}$ discurso da emancipação deve ser analisado do ponto de vista da parcialidade, pois há populações marginalizadas, que necessitam da defesa do estado por meio de políticas públicas que garantam os direitos humanos. Cabe ressaltar que são primordiais as campanhas de motivação para a mulher atuar na política e em ações sindicais, com visas ao seu empoderamento. Isso demonstra que os movimentos são lentos e a cultura é um dispositivo de poder sobre as estruturas sociais.

O preconceito que se observa no âmbito das relações sociais, como foi assinalado, não se limita à mulher apenas, mas aos grupos que não se encaixam nas padronizações homem, branco e heterossexual. Não raro, professores tendem a renunciar aos assuntos que envolvem a discussão desse tema na sala de aula, devido à complexidade cultural que o tema pressupõe. Portanto, torna-se clara a necessidade de uma discussão que fundamente a compreensão sobre o gênero 
na educação e no campo social, principalmente, de abordagens que desnaturalizam os discursos sobre as relações binárias de oposição (homem x mulher; razão x emoção, por exemplo) como único modo de se pensar a sexualidade.

Ao aprofundar estudos sobre o conceito de gênero, verifica-se uma importante reflexão circunscrita na tese de Judith Butler, que entende os discursos como instrumentos de opressão, ou seja, como modos de induzir e incitar os sujeitos a construírem, pela linguagem, uma ideia de si próprios. A ideia é a de tratar o gênero como efeito - e não causa - de instituições, discursos e práticas. Tal categoria é tratada não como um atributo que os sujeitos possuem, mas como um discurso sobre suas identidades.

Em termos culturais, grande parte das mulheres já percebeu que as relações de gênero são práticas construídas ao longo da história da humanidade, assim como as relações binárias, as relações de poder e as construções identitárias. Estão cientes, nesse sentido, de que podem ser desconstruídas em favor da igualdade social. De acordo com Bourdieu,

a ordem social funciona como uma imensa máquina simbólica que tende a ratificar a dominação masculina sobre a qual se alicerça: é a divisão social do trabalho, distribuição bastante estrita das atividades atribuídas a cada um dos sexos, de seu local, seu momento, seus instrumentos; é a estrutura do espaço, opondo o lugar de assembléia ou de mercado, reservados aos homens, e a casa, reservada às mulheres; [...] O mundo social constrói o corpo como realidade sexuada e como depositário de princípios de visão e de divisão sexualizantes (2007, p. 18).

Com essa visão de Bourdieu, legitima-se o que Giulani (2001) relata em seu estudo sobre o nível prático e o nível político das relações de gênero no campo de trabalho. As distribuições desiguais de trabalho sustentam o paradigma da dominação, que enfoca a diferença biológica do homem e da mulher. Fica claro entender que as diferenças sexuais se explicam naturalmente pela biologia dos corpos, que determinam a diferença social construída entre os gêneros. Considere-se, ainda, que apesar de uma mulher ter presidido a nação brasileira, a maioria ainda vem ocupando os bastidores e assessorando homens. Além disso, em regiões interioranas, o papel social da maioria das mulheres, sobretudo na faixa etária de 35 a 60 anos, circunscreve unicamente o universo doméstico. A realidade do município de Colombo não é diferente.

É verdade que a mulher tem ocupado novos espaços públicos. Também é perceptível que a mulher ressignificou o espaço doméstico como local de luta. 
Foi a partir dele que muitas manifestações alavancaram a busca da igualdade de direitos. Os movimentos feministas transportaram para a política alguns problemas que não eram considerados "políticos". As diferentes formas de violência contra a mulher, que não eram vistas como uma das preocupações entre as comunidades, ficando restrita aos debates familiares, atualmente são pautas de discussões nas bancadas do poder legislativo. Cabe, lembrar, por exemplo, que em 7 de agosto de 2006, o então Presidente da República do Brasil aprovou a Lei Maria da Penha - Lei de Violência Doméstica e Familiar contra a Mulher, $n^{\circ} 11.340$, projeto elaborado por um grupo interministerial a partir de um anteprojeto encampado por organizações não-governamentais. A partir da implantação dessa lei, houve mudanças na legislação e também a implementação da disciplina de "Educação em Direitos Humanos" no currículo de todos os níveis, por meio da Resolução no 01, de 30 de maio de 2012, que institui Diretrizes Curriculares Nacionais para a Educação em Direitos Humanos, fundamentada no Plano Nacional de Educação em Direitos Humanos (2007), da Secretaria Especial dos Direitos Humanos, do Ministério da Educação e Ministério da Justiça; e no Decreto n 7.037, de 21 de dezembro de 2009, que aprova o Programa Nacional de Direitos Humanos. Outras frentes relacionadas aos Direitos da Mulher e a luta pela igualdade de gênero se fortaleceram e ganharam mais visibilidade, como a ONU Mulheres e a Articulação das Mulheres Brasileiras.

O papel político da mulher na atualidade está fundamentado nos movimentos feministas que ajudaram a construir a história do fim do século XX e início do século XXI. A dimensão da força feminina é vista nas instituições de ensino, secretarias, organizações que tratam dos diversos assuntos que possuem como tema a mulher. É necessário, assim, transpor os muros das instituições que problematizam as desigualdades de gênero e estreitar caminhos entre estas e as comunidades mais necessitadas.

Ao salientar a importância dos debates acerca das desigualdades de gênero, Rosaldo (1979, p. 33) observou que "a mulher pode ser importante, poderosa e influente, mas parece que em relação ao homem de sua idade e de seu status social, a mulher em todo o lugar carece de poder reconhecido e valorizado culturalmente". As diferentes formas de representação da mulher, seja nos círculos sociais concretos, seja na tratativa que os veículos de informação dão às questões do universo feminino, podem ser co-responsáveis pela dominação 
masculina. A mídia contribui fortemente para a reprodução de imagens que perpetuam as oposições advindas do paradigma razão x emoção.

Outra observação pertinente está em problematizar o discurso do "politicamente correto", expressão que surge na década de 1990 com a mídia enfatizando a possibilidade de ascensão das mulheres e outras vozes oriundas da periferia. Com isso, pretendeu-se criar o sentido de aceitação do outro ao mesmo tempo, mas longe de uma perspectiva de equidade. Contudo, a própria mulher continua a ser depositária dos sentidos da relação dominante $\mathrm{x}$ dominado e seu corpo torna-se objeto de opressão, já que, a partir dele, cria-se um modelo de consumismo. É necessária a intervenção social na elaboração de uma nova consciência que deixe de valorizar a mulher a partir do corpo e passe a projetá-la no mundo como ser político e ideológico.

Embora a educação seja um processo permanente, que transcende o espaço e o tempo escolar, a escola é uma das territorialidades onde ocorre parte do desenvolvimento humano e, portanto, é um território fértil para problematizar culturas e reinventar novos discursos que empoderem as minorias, sobretudo as mulheres. A escola é um dos espaços onde os sujeitos deixam de ser indivíduos e passam a constituir uma coletividade. Nesse contexto, cumpre associar diferentes ações educativas que propiciem o diálogo entre as gerações. É o conhecimento sistematizado e orientado que possibilita a troca, já que a perspectiva pluricultural no âmbito da educação sofre resistência devido às ideologias dominantes que perpassam os espaços escolares e os discursos oficiais.

Assim, percebe-se que é fundamental as comunidades escolares adquirirem consciência de que a organização racional do mundo foi estabelecida sob uma ideologia de dominação. Um grupo cria para si uma hegemonia em detrimento de populações imensas, cujos lugares sociais, de subalternidade estão, por assim dizer, predeterminados. Desconstruir essa realidade posta, abrindo novos horizontes para uma vivência mais harmoniosa e justa é urgente. Nesse sentido, esta proposta de extensão buscará promover debates e ações que visam à emancipação das mulheres por meio do conhecimento dos seus direitos e dos dispositivos que garantam sua dignidade humana.

Pesquisas do IBGE publicadas em $2014^{4}$ no Portal Brasil apontam que $87,4 \%$ das famílias sem cônjuge é chefiada por mulheres e os dados da SIS (Síntese de Indicadores Sociais) mostram que de 2004 a 2014, subiu de 3,6\%

Os índices haviam sido atualizados até a consulta realizada em dezembro/2018. 
para $15,1 \%$ o número de famílias formadas por casais e filhos cuja responsabilidade econômica é atribuída às mulheres. Esses percentuais apontam que embora os homens ainda sejam predominantemente os chefes de família, as mulheres têm assumido cada vez mais a responsabilidade econômica, o que nos leva ao entendimento de que elas estão mais inseridas no mundo do trabalho e das produções de bens de consumo. No que se refere à renda dos brasileiros, os registros de 2014 mostram que as mulheres ganham até 75,4\% dos rendimentos do cônjuge, sendo que $37,2 \%$ recebem até $50 \%$ menos dos rendimentos do companheiro. A fatia de mulheres que recebem até um salário é de $30,6 \%$ e de homens é de $21,5 \%$. Os dados levam a compreensão de que há uma real necessidade de se pensar em estratégias para promover a formação política das mulheres que compõem a comunidade interna do Campus Colombo, das mulheres do município de Colombo, principalmente as que estão em situação de vulnerabilidade, visando à elevação da qualidade de suas vidas. Outro dado interessante é o Coeficiente de Gini, também utilizado para medir o índice de desigualdade social. De acordo com essa estatística, a distribuição de rendimento médio mensal de todos os trabalhos por sexo no Brasil está mais desigual, sendo 0,491 entre homens com ocupação e 0,474 entre mulheres com ocupação. Aliadas a isso estão as dificuldades de acesso à oferta de formação e qualificação profissional e cidadã que respeitem as peculiaridades e dificuldades desta parcela da população que tem uma tripla jornada de trabalho, pois, além da atividade laboral de subsistência (domésticas, cozinheiras, costureiras, entre outras), cuidam dos filhos, da casa e muitas ainda são responsáveis pelo cuidado dos familiares mais idosos. Essa realidade revela que a população feminina sofre o desprivilegio por estarem em condições desiguais em relação aos homens. É importante observar que essa fatia da população está mais concentrada nas periferias, de onde falam as minorias.

Aliadas a isso estão as dificuldades de acesso à oferta de formação e qualificação profissional e cidadã que respeitem as peculiaridades e dificuldades desta parcela da população que tem uma tripla jornada de trabalho, pois, além da atividade laboral de subsistência (domésticas, marisqueiras, costureiras, entre outras), como detectado nos 13 estados, cuidam dos filhos, da casa e muitas ainda são responsáveis pelo cuidado dos familiares mais idosos. Essa realidade revela que a população feminina sofre o desprivilegio por estarem em condições desiguais em relação aos homens. É importante observar que essa fatia da população está mais concentrada nas periferias e nas cidades interioranas. 
Diante do contexto, esta proposição abrange a população feminina na faixa etária acima de 18 anos, que busca oportunidades de acesso às ações educacionais e à inclusão e permanência no mundo do trabalho, tendo como ponto central a identificação, reconhecimento e valorização da diversidade e dos saberes acumulados em cada uma de suas etapas de vida.

Esta ação de extensão é significativa para o público esperado porque é criada de acordo com a identificação da experiência não-formal adquirida pela mulher ao longo da vida e de acordo com os seus anseios pessoais e profissionais, construindo-se um itinerário formativo personalizado. Dessa forma contribui para a ampliação do acesso à educação, visando à formação para o desenvolvimento pessoal e profissional. Para isso, é necessário planejar conhecimentos básicos que subsidiem a compreensão de saberes necessários para a formação técnica.

Por fim, a partir do projeto "Mulher e Mundo do Trabalho", pretende-se garantir o direito à educação, oportunidade de melhoria de vida e de trabalho. Ainda, visa à redução dos índices de miséria e pobreza, pela elevação dos níveis educacionais e impulso ao desenvolvimento econômico e social da região, com mais equidade e justiça social.

\section{PELAS MÃOS E PELAS MÃES}

O Projeto acontece nas salas de aula e Auditório da UAB, localizada no espaço da Prefeitura de Colombo - Regional Maracanã, sendo, eventualmente, utilizados outros espaços da Secretaria de Ação Social, Secretaria de Abastecimento e Campus Colombo.

As oficinas e palestras de formação ocorrem semanalmente, havendo dois grupos de trabalho concentrados nas quartas e quintas-feiras à tarde. Os trabalhos desenvolvidos partem do mesmo princípio metodológico, que problematiza os saberes já adquiridos na trajetória dos sujeitos envolvidos e avança para a sistematização desses saberes, orientando-se para novos caminhos e tecnologias associadas aos conteúdos trabalhados.

Observa-se que os produtos gerados nas oficinas são fundamentais para que as mulheres agreguem às suas experiências novas práticas, conscientizando-se da importância do trabalho, da educação e do papel da mulher na sociedade. Tais procedimentos somam-se à compreensão de que todo ser humano 
possui direitos e que é necessário cada vez mais apropriar-se dos diferentes conhecimentos produzidos e das novas linguagens para a emancipação social.

Cada participante tem um compromisso com o projeto, que é o de multiplicar os conhecimentos adquiridos, bem como as técnicas de artesanato, ensino suas filhas ou netas a produzir peças de artesanato em casa, utilizando matéria-prima reciclada ou com o menor custo possível, já que se tratam de famílias bastante carentes. Essa atitude agregou mais força aos laços familiares das mulheres, porque elas criam situações para dialogar em suas casas, mostrar que por meio da educação e do conhecimento suas vidas podem melhorar e, sobretudo, divulgar tudo o que aprenderam sobre os direitos da mulher. Assim, o projeto colabora também para uma rede de proteção entre as mulheres.

O debate promovido a partir das reflexões sobre a mulher e sobre as desigualdades de gênero balizam parte do trabalho realizado no projeto. Por isso, e com o apoio e financiamento da Pró-Reitoria de Extensão, Pesquisa e Inovação do IFPR, surgiu a proposição de criação do Núcleo Interdisciplinar de Ensino, Extensão, Pesquisa e Inovação em Direitos Humanos - NIEPIDH Campus Colombo, que se incumbe de discutir Direitos Humanos e Políticas para Mulheres, e envolver a comunidade interna e externa nesse debate.

Observa-se, diante do exposto, a real necessidade de fortalecimento das ações que versam sobre a desconstrução das desigualdades, sobretudo no que se refere às relações de gênero e o respeito à diversidade.

\section{CONSIDERAÇÕES FINAIS}

A metodologia da ação de extensão representa um instrumento facilitador no processo de implantação e implementação de políticas, projetos e ações que contemplem o acolhimento, a educação, a qualificação e formação profissional e tecnológica, a estruturação de empreendimentos, o acesso ao mundo do trabalho, o desenvolvimento sustentável de comunidades e inclusão de pessoas desfavorecidas e não tradicionais. Esta concepção de acesso prioritário aos sujeitos em situação de vulnerabilidade, que reconhece e valoriza os saberes construídos na comunidade, pretende trazer para o Instituto a oportunidade de estabelecer um diálogo com as diversidades, integrando o conhecimento acadêmico ao itinerário formativo de mulheres e das populações não tradicionais. 
Salienta-se a importância da interface e do diálogo com a comunidade por meio deste projeto, o que permite à instituição de ensino aproximar-se da realidade e do contexto das comunidades e das mulheres, conhecê-las e compreendê-las, identificando seus sonhos, suas necessidades, desafios e demandas, contribuindo, assim, para a definição de suas diretrizes. Nesse sentido, a abordagem dos conhecimentos é prioritariamente dialógica, cujos conteúdos propostos na organização curricular são pautados em um processo planejado, articulado e integrado, que seja capaz de favorecer e fomentar o desenvolvimento integral e sustentável das participantes.

Nessa perspectiva, é importante a articulação, integração e utilização das estruturas e serviços de suporte e apoio - serviço social, psicologia, assistência estudantil, saúde, direitos da mulher, etc., formando uma rede colaborativa, constituída de serviços ofertados pela própria Instituição e em parceria com a Prefeitura Municipal de Colombo, que melhorem e ampliem a capacidade de atendimento, visando a responder adequadamente à diversidade desse grupo de educandas e de suas demandas sociais, educacionais e profissionais.

Esse contexto demanda a elaboração de planos de ação específicos que articulem a formação e a conexão com o trabalho. Nesse sentido, o projeto destaca que é importante considerar, além das habilidades demandadas pelas mulheres, as potencialidades econômicas existentes, para detectar a vocação econômica local e, a partir daí, estabelecer parcerias com as entidades e empresas, visando à inserção das educandas no mundo produtivo. Como consequência dessa ação, pretende-se que as educandas tenham diversas alternativas de mobilidade no mundo do trabalho.

Diante do exposto, cumpre destacar o trabalho de percepção individual e coletiva das turmas que fizeram parte do Projeto "Mulher e Mundo do Trabalho". Assim, são desenvolvidas atividades como dinâmicas que provoquem as mulheres para a reflexão sobre temas/assuntos a serem trabalhados no encontro; atividades com gêneros textuais, envolvendo oralidade, leitura e escrita; momentos de confraternização; direcionamentos para a aprendizagem voltada à empregabilidade ou empreendedorismo, seja pelo desenvolvimento de atitudes empreendedoras, seja pela aprendizagem de confecção de um produto; avaliação do trabalho desenvolvido em função dos objetivos do projeto; distribuição de tarefas a algumas das participantes, envolvendo-as ativamente no planejamento do encontro seguinte: por exemplo, organização do espaço, coleta de materiais para as oficinas e até mesmo o lanche. 
Por fim, destaca-se o alcance das ações do projeto, que já atendeu cerca de 200 mulheres e atualmente integra a agenda da Secretaria de Ação Social do município de Colombo, participando diretamente de todas os eventos realizados com as mulheres colombenses.

\section{REFERÊNCIAS}

BOURDIEU, Pierre. A dominação masculina. Trad. Maria Helena Kühner. 5 ed. Rio de Janeiro: Bertrand Brasil, 2007.

BRASIL. Ministério da Educação. Programa Nacional Mulheres Mil - Guia Metodológico. Brasília, s/d.

Educação, Cidadania e Desenvolvimento Sustentável. Brasília, 2011. Disponível em: http://mulheresmil.mec.gov.br/index.php?option=com_content\&view=arti cle\&id=47\&Itemid=53\&lang=br\# content. Acesso em: 15 out. 2011.

. Ministério do Planejamento, Orçamento e Gestão; Instituto Brasileiro de Geografia e Estatística. Estatística de Gênero - Uma análise dos resultados do Censo Demográficos 2010. Rio de Janeiro: IBGE, 2014.

BUTLER, Judith. Problemas de Gênero: o feminismo e a subversão da identidade. 15 ed. Rio de Janeiro: Civilização Brasileira, 2017.

CAMPOS, Maria Consuelo Cunha. Gênero. In: Jobim, José Luís (org.). Palavras da crítica. Rio de Janeiro: Imago Editora, 1992.

FREIRE, Paulo. Pedagogia da autonomia: saberes necessários à prática educativa. 43 ed. São Paulo: Paz e Terra, 2011.

GIULANI, Paola Cappelin. Os movimentos de trabalhadoras e a sociedade brasileira. In: DEL PRIORE, M. (Org.) História das mulheres no Brasil. 5 ed. São Paulo: Contexto, 2001, p. 640-667.

ROSALDO, Michelle Zimbalist. A mulher, a cultura e a sociedade: uma revisão teórica. In: A mulher, a cultura e a sociedade. Trad. Cila Ankier e Rachel Gorenstein. Rio de Janeiro: Paz e Terra, 1979, p. 33-64.

TIBURI, Márcia. Feminismo em comum - para todas, todes e todos. Rio de Janeiro: Rosa dos Tempos, 2018. 